Editorial

\title{
Letter from the Editor: Special Issue on the 2021 Peter J. Buckley and Mark Casson AIB Dissertation Award
}

\author{
John Mezias, Editor ${ }^{1}$ \\ 1 University of Miami, USA \\ Keywords: dissertation award \\ https://doi.org/10.46697/001c.30711
}

\section{AIB Insights}

Vol. 21, Issue 4, 2021

Since 2013, AIB Insights has dedicated an issue to finalists for the prestigious Peter J. Buckley and Mark Casson AIB Dissertation Award. For the ninth consecutive year, we proudly feature articles by the 2021 award finalists summarizing insights from their cutting-edge dissertation research.

Welcome to AIB Insights' annual AIB Dissertation Awards special issue. Since 2013, AIB Insights has dedicated an issue for finalists of the prestigious Peter J. Buckley and Mark Casson AIB Dissertation Award to provide executive summaries of their dissertations. For the ninth consecutive year, we proudly feature articles by the award finalists summarizing insights from their cutting-edge dissertation research. As is our tradition, our first article is by the dissertation award winner, who is Rachel Pacheco. We then sequence the other articles using alphabetical order of authors' names.

Rachel Pacheco from the University of Pennsylvania (PhD awarded by University of Pennsylvania) summarizes her dissertation on "A Contingent Theory of Governance for the Global Project Organization: The Effect of Diversity and Composition on Order and Conflict.” Dr. Pacheco examines large global project organizations such as building road networks or power plant development. Specifically, she investigates how the project's structure and the concentration of power among participants affect resource allocations, conflicts, and performance. She provides recommendations for those funding, participating in, and managing large global projects.

Jelena Cerar from WU Vienna (PhD awarded by WU Vienna) summarizes her dissertation on "Headquarters Resource Allocation within Multinational Corporations: Antecedents, Consequences, and Related Methodological Issues.” Dr. Cerar explores how top manager's biases affect headquarters-subsidiary relationships in multinational companies. In particular, she studies headquarters roles and decision processes in subsidiary initiatives. Her results include counterintuitive findings related to recourse allocation across subsidiary networks and provide insights for headquarter managers and expatriates.

Tuuli Hakkarainen from Bocconi University (PhD awarded by Aalto University) summarizes her dissertation on "Sharing expertise within the MNC.” Dr. Hakkarainen's dissertation studies how new forms of collaboration within Multinational Corporations, such as virtual interacting, can mitigate challenges of sharing expertise which is different from knowledge transfer. She notes how the Covid-19 pandemic has accelerated the need for increasingly fluid methods to both develop and share expertise needed to ensure global collaborations succeed. Her research has implications for both domestic and multinational organizations.

Johannes Kleinhempel from University of Manchester (PhD Awarded by University of Groningen) summarizes his dissertation on "Essays in Comparative International Entrepreneurship Research.” Dr. Kleinhempel's dissertation utilizes several essays to evaluate socio-cultural influences on entrepreneurship in different contexts. His comparative research provides insights into how theoretical structuring and testing affect our understanding of how socio-cultural conditions affect entrepreneurship.

Finally, Nan Zhang from California State University Stanislaus (PhD Awarded by University of Illinois at UrbanaChampaign) summarizes her dissertation titled "Four Studies on Antitrust Enforcement and Foreign Investment Activities.” Dr. Zhang's dissertation details how the global financial crisis of 2008 spurred anti-globalization sentiments and actions that have started to adversely affect foreign direct investment. Her research investigated how some governments are using antitrust enforcement to curtail aggregated foreign investment in domestic mergers and acquisitions, and how these actions may differentially affect greenfield investments.

Lastly, I wish to thank the vital work of reviewers for this issue. On behalf of the AIB community, I also wish to thank the 2021 Buckley and Casson AIB Dissertation Award Selection Committee for their indispensable efforts and dedicated service: Marcus Larsen (Chair), Tatiana Kostova, Catherine Welch, and Sjoerd Beugelsdijk. 